Journal of Communication Disorders, 44, 601-614, doi:10.1016/j.jcomdis.2011.07.004

\title{
Intentional communication in nonverbal and verbal low-functioning children with autism
}

\author{
Jarymke Maljaars ${ }^{1}$, Rianne Jansen ${ }^{2}$, Ilse Noens ${ }^{2}$, Evert Scholte ${ }^{1}$ \& Ina van Berckelaer-Onnes ${ }^{1}$ \\ ${ }^{1}$ Leiden University, the Netherlands; ${ }^{2}$ Katholieke Universiteit Leuven, Belgium
}

\begin{abstract}
In this study we characterized profiles of communicative functions and forms of children with autism and intellectual disability $(n=26)$, as compared to typically developing children $(n=26)$ with a comparable nonverbal mental age ( $2-5$ years). Videotapes of the Communication and Symbolic Behavior Scales - Developmental Profile were analyzed using a standardized observation scheme in which three main functions were distinguished: behavior regulation, social interaction, and joint attention. Different forms of communication were also investigated: gestures, vocalizations / verbalizations, and eye gaze. Results indicated that in typically developing children the proportion of communication for the purpose of joint attention was much higher than for behavior regulation, whereas in children with autism the opposite pattern was seen. Low-functioning nonverbal children with autism mainly communicated for behavior regulation and not or only rarely for declarative purposes. Generally, this subgroup used the least complex forms to communicate. Low-functioning verbal children with autism differed from typically developing children only in the rate, not in the proportion of communication for specific functions. Combinations of three different communicative forms were used by verbal children with autism less frequently than by typically developing children.
\end{abstract}

Keywords: autism, intellectual disability, intentionality, communicative functions, behavior regulation, joint attention

\section{Introduction}

\section{Communication in low-functioning children with ASD}

Impairments in communication are among the most important features of autism spectrum disorders (ASD), and involve both verbal and nonverbal communication (APA, 2000). However, communication skills are extremely heterogeneous in individuals with ASD, particularly in children with an associated intellectual disability (ID). A large proportion of low-functioning individuals with ASD does not develop language or acquires at most a few functional words or signs (Boucher et al., 2007). Exact percentages of nonverbal individuals with ASD are difficult to determine, because of increased recognition of ASD in higher functioning and verbal individuals (Lord et al., 2004). Since research mainly focused on toddlers with ASD or higher functioning individuals with ASD, relatively little is known about language abilities and communication in children with ASD and ID (Boucher et al., 2007; Tager-Flusberg et al., 2005). Therefore, the purpose of this study was to identify the

NOTICE: this is the author's version of a work that was accepted for publication in Journal of Communication Disorders. Changes resulting from the publishing process, such as peer review, editing, corrections, structural formatting, and other quality control mechanisms may not be reflected in this document. Changes may have been made to this work since it was submitted for publication. A definitive version was subsequently published in Journal of Communication Disorders, 44, 601-614, doi:10.1016/j.jcomdis.2011.07.004. 
functions and forms of communication in verbal and nonverbal children with autism (AD) and associated ID, so as to evaluate their strengths and weaknesses in intentional communication.

\section{Functions of communication in ASD}

Limited intentionality is considered to be a core deficit in the communication of individuals with ASD (Noens \& Van-Berckelaer-Onnes, 2005; Travis \& Sigman, 2001; Wetherby et al., 2000). Usually, intentionality is first seen when children start to use proto-imperative and proto-declarative expressions between 9 and 11 months of age (Bates, 1979). By the end of the first year of life, typically developing children communicate for a large number of functions, which can be grouped into three main functions: (a) behavior regulation, (b) social interaction, and (c) joint attention ${ }^{1}$ (Shumway \& Wetherby, 2009). Hence, communicative intentionality for different functions develops before the emergence of language by use of gestural and vocal communicative acts (Wetherby, 1986).

Several studies found a significantly lower rate of intentional communication in children with ASD compared to typically developing (TD) children or children with developmental delays (DD) (e.g., Chiang et al., 2008; Shumway \& Wetherby, 2009). So far, a few studies into communication profiles of children with ASD have been conducted, but differences with respect to child characteristics (e.g., chronological age, level of functioning, verbal ability), and research methods (e.g., instruments, situations, and criteria used to assess intentional communication) complicate comparability of these studies. The most common finding in systematic observation of communication profiles in young children with ASD is a reduced rate of communication for all different communicative functions compared to children with TD or DD (Shumway \& Wetherby, 2009), with the exception of initiation of acts for behavior regulation. Some studies reported reduced behavior regulation compared to TD children (Adrien et al., 2001; Chiang et al., 2008; Wetherby et al., 2007), but not compared to children with DD or ID (Stone et al., 1997; Viellard et al., 2007).

Several studies analyzed the proportions of communicative functions, thus determining patterns of communicative functions independent of the frequency of communication. Studies in young children with ASD reported a propensity to communicate for behavior regulation rather than for joint attention (Adrien et al., 2001; Shumway \& Wetherby, 2009; Stone et al., 1997; Viellard et al., 2007). However, Chiang and colleagues (2008) only observed a lower proportion of joint attention in ASD, but equal proportions for behavior regulation and social interaction compared to TD children. With respect to social interaction, the least stable outcomes were found. Some studies described the initiation of social interaction as a relative strength (e.g., Shumway \& Wetherby, 2009), while other studies (e.g., Adrien et al., 2001) reported social interaction together with joint attention as striking weaknesses.

Typically developing children learn to use different functions simultaneously (Bruinsma et al., 2004), whereas children with ASD seem to develop the different functions consecutively. In ASD, development of communicative intentionality appears to follow a sequence from behavior regulation and social interaction to joint attention (Calloway et al., 1999; Crais et al., 2004). They continue to make progress in the use of different communicative functions as they get older

\footnotetext{
${ }^{1}$ The term 'joint attention' refers in this paper to a specific communicative function and therefore is used in a broader definition than usual in autism literature.
} 
(Calloway et al., 1999; Travis \& Sigman, 2001). Yet, most prior studies of communication profiles in ASD focused on very young children only. Consequently, less is known about the relationship between level of functioning, language abilities, and communication profiles in ASD.

Intentionality has a central role in the acquisition of language (Bloom \& Tinker, 2001). In typical development, joint attention abilities in young children are significantly related to expressive language (Carpenter et al., 1998; Delinicolas \& Young, 2007; Mundy \& Gomes, 1998; Watt et al., 2006). Mundy and colleagues (1995) also reported a link between behavior regulation and social interaction on the one hand and expressive and receptive language abilities on the other. With respect to children with ASD, several studies found a predictive relationship between joint attention and expressive language development (Dawson et al., 2004; Drew et al., 2007; McDuffie et al., 2005). Studies examining several communicative functions found that behavior regulation and social interaction were not significantly related to language development in ASD (Mundy et al., 1990; Watt et al., 2006). The study of Stone and Caro-Martinez (1990) demonstrated a wider range of communicative functions in verbal children with autism compared to nonverbal children with autism. According to the study by Wetherby and colleagues (2007), acts for behavior regulation and joint attention in the second year of life were significantly related to nonverbal intelligence at three years of age. Most of the other studies did not find a correlation between nonverbal intelligence and communicative functions in ASD (Charman et al., 2003; Shumway \& Wetherby, 2009). All these studies focused on relatively young children with ASD and not specifically on children with associated ID.

\section{Forms of communication in ASD}

Communicative intentions can be expressed in several ways, differing in quality from very primitive forms (such as pulling one's hand) to more conventional forms (such as spoken language). Forms can be analyzed by focusing on quantity, diversity, or complexity. Previous studies revealed that in children with ASD eye gaze was seen less frequently and less integrated with other communicative forms (Stone et al., 1997). Children with ASD also used less pointing than TD children (Shumway \& Wetherby, 2009; Stone et al., 1997), especially for joint attention purposes (Camaioni et al., 2003; Goodhart \& Baron-Cohen, 1993). Children with ASD often compensate their reduced use of gestures and eye gaze with more primitive or unconventional forms, such as manipulations of hands or body (Freeman et al., 2002; Shumway \& Wetherby, 2009; Stone et al., 1997). With respect to diversity, children with ASD showed a decreased variety in type of gestures (Colgan et al., 2006). In general, results on quantity and diversity of communicative forms are unambiguous, whereas the possible differences in complexity seem to be less clear. Complexity refers to the degree by which communicative gestures are accompanied by eye gaze and/or vocalizing. Shumway and Wetherby (2009) reported no differences in combinations of forms used for behavior regulation, social interaction, and joint attention in young children with ASD when compared to TD children (aged between 18 and 24 months). However, a substantial variance within the ASD group was observed for the different levels of complexity. Therefore, they recommended further research into possible changes across the first years of life. Another study (Stone et al., 1997) reported significant differences in level of complexity between children with DD or language impairment and children with ASD. The latter of the two groups used a significantly lower proportion of acts involving a combination of gestures, vocalizations, and eye gaze, although no differentiation was made for the specific communicative functions. 


\section{Implications of communication problems in ASD}

Together with the restricted use of (non)verbal symbolic communication forms, the limited communicative intentionality in ASD leads to reduced possibilities to control, understand, and participate in the social world. These communication impairments can result in challenging behavior, in particular in low-functioning nonverbal individuals (Chiang, 2008; McClintock et al., 2003; Sigafoos, 2000), and are a major stressor for parents (Bebko et al., 1987; Konstantareas \& Homatidis, 1989; Lecavalier et al., 2006). In addition, the development of communication and language predicts better long-term outcomes (Mahwood et al., 2000), and improvement in communicative skills is closely related to reduction of challenging behavior (Goldstein, 2002; Van Berckelaer-Onnes et al., 2002). Therefore, research into the communication abilities of lowfunctioning children with ASD is essential. Research into low-functioning individuals with ASD is more complex, as severe communication problems make it harder to use standardized instruments and result in limitations in testability (Eagle, 2002). By using direct observation with a precise measure to describe and quantify communicative functions and forms, important information on the communicative weaknesses, but also on the communicative strengths can be provided. This will improve our understanding of the communication profiles of low-functioning children with ASD. For both verbal and nonverbal low-functioning children with ASD, it is important to characterize intentional communication skills in rate and quality, so as to provide important intervention targets to enhance intentional communication (Bruinsma et al., 2004; lacono et al., 1998).

\section{Purpose of the study}

The main purpose of the current study was to explore the profile of intentional communication in low-functioning verbal and nonverbal children with autism (AD) compared to typically developing (TD) children matched on nonverbal mental age. Two important aspects of intentional communication were taken into account; first, the functions or purposes underlying the communicative efforts of the children, and second, the complexity of forms of the communication they use. The aims of this study were: (a) to assess the differences in rate and proportion of communicative functions between low-functioning children with $A D$ (both as a whole and divided into verbal and nonverbal subgroups) and TD children, (b) to investigate the relationship between nonverbal mental age, language abilities, and proportion of use of these communicative functions in the $A D$ and TD groups, and (c) to examine differences in complexity of communicative forms used for the different communicative functions between verbal and nonverbal children with $A D$ and ID compared to TD children. Based on the studies in toddlers with ASD, we expect a different communication profile in children with $A D$ and ID compared to TD children with a tendency to communicate for behavior regulation rather than social interaction or joint attention. Furthermore, lower levels of complexity are expected in the AD and ID group, since children with ASD show difficulties in integrating different communicative forms. A relation between language and communication functions, especially joint attention, may be expected. Therefore, it is important to distinguish communication profiles regarding function and complexity of forms for verbal and nonverbal children with AD. 


\section{Method}

\section{Participants}

Fifty-two children were included in this study. The main characteristics of the participants are presented in Table 3.1. The total autism group (AD group) comprised 26 children with autism and intellectual disability, whom all had received a formal classification of autistic disorder according to DSM-IV-TR criteria (299.00; APA, 2000) prior to the study. Diagnosis was confirmed by an algorithm score above the threshold for autism on the Autism Diagnostic Observation Schedule Modules 1 or 2 (ADOS; Gotham et al., 2007), and a classification of autistic disorder on the Diagnostic Interview for Social and Communication Disorders - version 11 (DISCO-11; Wing, 2006). Levels of ID ranged from mild to severe (APA, 2000) based on a standardized intelligence test. Given the classification difficulties in low-functioning individuals, this study focused on the core syndrome instead of the whole spectrum to create a more homogeneous group. Participants ( 23 boys; 3 girls) were aged between $3 ; 1$ and $11 ; 4$ years $(M=7 ; 1, S D=2 ; 6)$. The nonverbal mental age ranged from 26 to 68 months $(M=39.7, S D=11.1)$. Children with severe physical disabilities were excluded, since standard criteria for the identification of intentionality in communication are difficult to apply in this population (lacono et al., 1998).

Table 3.1 Main characteristics of the participants

\begin{tabular}{|c|c|c|c|c|c|c|c|c|c|c|}
\hline & \multirow{2}{*}{\multicolumn{3}{|c|}{$\begin{array}{c}\text { AD+ID group } \\
\text { Total } \\
(n=26)\end{array}$}} & \multicolumn{4}{|c|}{ AD+ID subgroups } & \multirow{2}{*}{\multicolumn{3}{|c|}{$\begin{array}{c}\text { TD group } \\
\text { Total } \\
(n=26)\end{array}$}} \\
\hline & & & & \multicolumn{2}{|c|}{$\begin{array}{l}\text { Nonverbal } \\
\quad(n=13)\end{array}$} & \multicolumn{2}{|c|}{$\begin{array}{l}\text { Verbal } \\
(n=13)\end{array}$} & & & \\
\hline & Range & $M$ & $S D$ & $M$ & $S D$ & $M$ & $S D$ & Range & $M$ & $S D$ \\
\hline Chronological age $^{\text {a }}$ & $37-136$ & 85.2 & 30.2 & 84.1 & 33.8 & 86.2 & 27.6 & $24-47$ & 35.4 & 5.9 \\
\hline Nonverbal mental age ${ }^{a}$ & $26-68$ & 39.7 & 11.1 & 34.7 & 5.5 & 44.8 & 13.1 & $29-65$ & 40.8 & 10.0 \\
\hline Receptive language $^{\text {a }}$ & $<14^{b}-53$ & 28.3 & 12.1 & 18.6 & 7.4 & 38.0 & 6.9 & $27-75$ & 43.8 & 11.4 \\
\hline Expressive language $^{a}$ & $<18^{b}-55$ & 31.8 & 12.8 & $-c$ & $-c$ & 41.7 & 7.8 & $22-67$ & 43.5 & 9.9 \\
\hline
\end{tabular}

Note. $\mathrm{AD}=$ autistic disorder; ID = intellectual disability; TD = typical development

a age / age equivalent in months; ${ }^{b}$ minimum score; ${ }^{c}$ nearly all cases achieved an age equivalent nearby or below the minimum score

Each participant in the AD group was individually matched with a TD child by nonverbal mental age within 3 months, measured with the Snijders-Oomen Non-Verbal Intelligence Test Revised 21/2-7 years (SON-R; Tellegen et al., 1998). Therefore, the groups did not differ in SON-R scores $\left(t_{\left(5^{0}\right)}=-.36, p=.72\right)$. The children in the TD group did not meet diagnostic criteria for autism spectrum disorder on the ADOS nor the DISCO. Age of the participants in the TD group (11 boys; 15 girls) ranged from $2 ; 0$ to $3 ; 11$ years $(M=2 ; 11, S D=0 ; 6)$. The TD group differed from the AD group on age $\left(t_{(50)}=8.24, p<.001\right)$ and $\operatorname{sex}\left(\chi_{(1)}^{2}=12.24, p<.001\right)$, but there was no difference in rate of intentional communication between boys and girls in the control group $\left(t_{(24)}=1.2, p=.25\right)$. Concerning the different communicative functions, boys in the TD group communicated more often for joint attention than girls, $\left(t_{(24)}=2.5, p=.02\right)$. The impact of chronological age on the findings is negligible, since no significant and only weak correlations were found between chronological age, total rate of intentional communication, and the use of the three different functions in the AD group (see also Table 3.4).

For some analyses the AD group was subdivided into verbal and nonverbal subgroups. The children in the nonverbal group $(n=13)$ used no verbalizations or only one-word utterances during 
the Behavior Sample. Those with verbal abilities $(n=13)$ mainly used two- or multiword utterances based on the observation of communicative forms during the CSBS-DP Behavior Sample. All children in the TD group had phrase speech, except for one of the youngest children. The characteristics of the subgroups are presented in Table 3.1.

The verbal $A D$ group did not differ from the typical control group on language production $\left(t_{(37)}=-.59, p=.56\right)$ and language comprehension $\left(t_{(37)}=-1.67, p=.10\right)$. The three groups were not comparable with respect to nonverbal mental age $\left(F_{(2,49)}=3.37, p=.04\right)$. The nonverbal AD group was significantly lower functioning than the verbal AD group and the TD group $(p=.05)$, but the verbal $A D$ group did not differ significantly from the TD group $(p=.60)$.

\section{Instruments}

Intentional communication. The Communication and Symbolic Behavior Scales - Developmental Profile Behavior Sample (CSBS-DP; Wetherby \& Prizant, 2002) is a structured assessment that encourages spontaneous communicative behavior. Six situations, such as play with a wind-up toy, a balloon, bubbles, or a book, offer the opportunity for the child to communicate. Intentional communication ratings were collected from CSBS-DP videotapes by two trained observers. Communication was coded during all Behavior Sample activities with exception of the comprehension probes. Every communicative act was coded (consistent with Shumway \& Wetherby, 2009) to allow more in-depth analyses. The standard CSBS-DP scoring is restricted to a maximum of three communicative acts per activity and therefore has less opportunity to discriminate between the groups. Moreover, the norms for the CSBS-DP only go through 24 months of age. Therefore, only the materials and testing procedure and not the standard scoring procedure of the CSBS-DP were used.

To examine the communicative profiles, videotapes of CSBS-DP Behavior Samples were analyzed using a standardized observation scheme (based on Wetherby \& Prizant, 1993), making it applicable to a broader (developmental) age range. A communicative act was determined using Wetherby and Prizant's (1993) criteria for intentional communication. An intentional communicative act requires a gesture, vocalization, or verbalization, that is directed toward the adult and that serves a communicative function. Gestures are directed when it concerns a movement toward, or touching the other person, or when combined with eye gaze or vocalization / verbalization. A vocal / verbal act must be accompanied by a gesture or eye gaze. Eye gaze alone and undirected vocalizations / verbalizations are not considered as intentional communication. Furthermore, only intentional communicative acts which were spontaneously initiated by the child were coded. The following rules were used to determine the spontaneity of communication: (a) only communicative acts following natural cues or manipulations of natural cues (e.g., presence or movement of objects, comments, or gestures) were coded, (b) communicative acts following a question or a direct prompt, or imitations were not included, and (c) non-interactive communicative acts such as utterances used to direct one's own actions, labeling objects, or emotional responses to a situation not directed to an adult were also excluded.

After identifying a communicative act, the function and form(s) used for this act were determined. Three mutually exclusive, main categories of communicative functions were coded: Behavior Regulation (BR), Social Interaction (SI), and Joint Attention (JA), according to the definitions described by Wetherby and Prizant (1993) (see Table 3.2 for definitions and examples). Due to the 
broader age range and verbal language abilities of this study compared to the target group of the CSBS-DP the specific functions within the categories SI and JA were extended with functions often seen in older, more verbal children, like expressing feelings or sharing information (based on Buckley, 2003; Calloway et al., 1999). A fourth category was used for functions which were unclear or did not fit into one of the three categories, for example unintelligible, incomplete, and incoherent sentences which did not fit in the context in the communicative situation or touching another person without clear communicative intent.

Table 3.2 Description of the main categories of communicative functions and forms (based on Wetherby \& Prizant, 1993)

\begin{tabular}{|c|c|c|c|}
\hline Category & & Description & Examples \\
\hline \multirow[t]{3}{*}{ Functions } & Behavior Regulation & $\begin{array}{l}\text { Acts used to regulate } \\
\text { another's behavior to } \\
\text { obtain a specific result }\end{array}$ & $\begin{array}{l}\text { - request object / action } \\
\text { - protest object / action }\end{array}$ \\
\hline & Social Interaction & $\begin{array}{l}\text { Acts used to gain or } \\
\text { maintain another's } \\
\text { attention to oneself }\end{array}$ & $\begin{array}{l}\text { - request social routine / comfort / permission } \\
\text { - call / greet / show off } \\
\text { - express feelings / interest }\end{array}$ \\
\hline & Joint Attention & $\begin{array}{l}\text { Acts used to direct } \\
\text { another's attention to an } \\
\text { object, event, or topic }\end{array}$ & $\begin{array}{l}\text { - comment on object / action } \\
\text { - request / provide information } \\
\text { - share pleasure / feelings }\end{array}$ \\
\hline \multirow[t]{3}{*}{ Forms } & Gestures & $\begin{array}{l}\text { Gestures } \\
\text { Manipulations of persons / } \\
\text { objects and movements of } \\
\text { objects }\end{array}$ & $\begin{array}{l}\text { - reach / touch point / distal point } \\
\text { - instrumental / descriptive gestures } \\
\text { - nod/shake head } \\
\text { - manipulate person's hand/body } \\
\text { - move object toward / away from person } \\
\text { - give / show object }\end{array}$ \\
\hline & $\begin{array}{l}\text { Vocalizations / } \\
\text { Verbalizations }\end{array}$ & $\begin{array}{l}\text { Use of vocal or verbal } \\
\text { communication }\end{array}$ & $\begin{array}{l}\text { - laugh / cry } \\
\text { - meaningless / meaningful transcribable } \\
\text { vocalizations } \\
\text { - verbalizations (single- / multiword spoken } \\
\text { utterances) }\end{array}$ \\
\hline & Eye gaze & $\begin{array}{l}\text { Gaze toward a person's } \\
\text { face immediately before, } \\
\text { during, or after the act }\end{array}$ & \\
\hline
\end{tabular}

Forms used during the communicative acts were coded as gestures, vocalizations / verbalizations, and/or eye gaze. The forms coded within the main categories of gestures and vocalizations are mutually exclusive. The (combination of) forms used for communicative acts were divided into three different levels of complexity. Level 1 is used for communicative acts with only one form (gesture), and thus represents the least complex acts. Level 2 reflects an intermediate level of complexity, involving a combination of two different communicative forms, a combination of a gesture with either eye gaze or a vocalization, or a vocalization with eye gaze. Level 3 concerns the most complex level of communicative acts, in that a combination of three forms is used by the child: gesture, vocalization, and eye gaze (based on Stone et al., 1997).

Coding was conducted by two of the authors (JM and RJ). To assess inter-rater reliability, the two raters independently double-coded $27 \%$ of all videotaped Behavior Samples. Both authors were aware of the aims of the study, but the second researcher was blind to the children's clinical diagnosis and scores on the other measures. Inter-rater reliability was calculated using percentage agreement and intra-class correlations. Agreement between the two coders was computed as a percentage of scores for which the observers completely agree compared to the jointly observed communicative acts, across 14 randomly selected participants ( 7 of these were drawn from the AD 
group and 7 from the TD group). Percentage agreement was uniformly above $89 \%$ for identification of communicative acts ( $M=96.2 ; 95 \%$ confidence interval: 94.0 - 98.5). Agreement for functions ranged from 80 to $92 \%$, and for forms from 82 to $94 \%$. The intra-class correlation coefficient for identification of communicative acts (rates per minute) was .96 (95\% confidence interval: .68 - .99). The generalizability coefficients for rates / percentages of function categories were $.70 / .82$ for function unclear, .90/.98 for BR, .92/.92 for SI, and .99/.97 for JA. The coefficients for the rates of form categories were .95 (gestures), .96 (eye gaze), and .99 (vocalization / verbalization). All agreement percentages and intra-class correlations, except for the rate of the unclear function category, exceed .80, indicating a good to excellent reliability. The unclear function category is left out of consideration in most of the analyses.

Nonverbal mental age and language abilities. To determine nonverbal mental age a Dutch test for nonverbal intelligence, the SON-R 21/2-7 (Tellegen et al., 1998) was used. Language abilities were individually assessed using the Reynell test for Dutch language comprehension (Van Eldik et al., 1995) and the Schlichting test for Dutch language production (Schlichting et al., 1995). The Reynell is an adaptation of the Reynell Developmental Language Scales (Reynell, 1985) and involves only tasks for verbal comprehension. The Schlichting measures expressive vocabulary requiring the naming of objects and pictures. Raw scores were converted into age equivalents. All three instruments have been found reliable and valid; internal consistency was above .80 and test-retest reliability ranged from .69- .82 (Evers et al., 2009).

\section{Procedure}

Participants with $A D$ were recruited from several special schools and special day care centers for children with ID in the Netherlands. TD children visited regular day care centers or nurseries. First, informed parental consent was obtained. Subsequently, all participants were assessed using the same instruments. In the first three sessions at school or day care, participants were given the SONR, Reynell, and Schlichting. The DISCO-11 interview was conducted in the parents' home. Thereafter, the child and one of the parents were invited to visit the university, school, or day care of the child, where the ADOS and the CSBS-DP were administered. The ADOS and CSBS-DP were video-recorded for later rating.

\section{Data analyses}

SPSS 17.2 was used to conduct the analyses. Prior to analyses, the coded communicative acts were transformed into rates-per-minute to control for variations in the duration of the Behavior Sample for each child. The mean duration for the AD group was 17.2 minutes (range: $7.3-28.7, S D=5.1$ ) and for the TD group 17.3 minutes (range: 12.0 - 23.5 minutes; $S D=2.6$ ). Furthermore, proportion of functions and forms were computed based on the total amount of communicative acts of the child. All frequency counts were acceptable to convert into rate and proportion metrics, since positive and linear relations were found between numerators and denominators, except for the function category unclear (Yoder \& Symons, 2010).

All data were tested for normality and proportional data were arcsine transformed prior to statistical tests (Cohen et al., 2003). Several independent sample $t$-tests were computed to identify possible differences between the TD group and the AD group in total rate of communicative acts, and rates and proportions of communicative functions. Given the number of $t$-tests conducted, a 
Bonferroni correction was applied to the analyses, resulting in an adjusted significance level of $p<$ .006. Cohen's $d$ was computed as a measure of effect size. Repeated measures mixed analyses of variance were used to compare groups profiles on communicative functions, with one betweensubjects factor of group ( $A D$ and $T D$ ), and one within-subject factor of function (BR, SI, and JA). Further, separate analyses for both groups were conducted to test differences in function within the two groups. Pearson correlations were calculated to examine the relationships between the proportions of communicative functions and other developmental characteristics. Bonferroni correction was applied for multiple comparisons, resulting in an adjusted significance level of $p<$ .0015. A series of one-way analyses of variance were conducted to analyze group differences on communicative functions for two AD groups (verbal and nonverbal) and the TD group. The adopted significance level after Bonferroni correction was $p<.006$. Significant effects were followed up with post hoc tests to evaluate differences among the three groups. The Games-Howell procedure was used, because the variances between the groups were unequal. Analyses of covariance were also run to control for the influence of differences in nonverbal mental age results between the three subgroups. Differences in complexity of communicative forms were studied for the separate function categories using several one-way analyses of variance with an adjusted significance level of $p<.01$ after Bonferroni correction. Since the variances were equal for all levels of complexity, Bonferroni post hoc tests were conducted to provide pairwise comparisons. Eta squared was used as a measure of effect size.

\section{Results}

\section{Differences in rate and proportion of communicative functions}

Table 3.3 presents mean rates of communicative acts per minute for the two groups during the Behavior Sample.

Table 3.3 Rate and proportion of communicative functions for AD and TD group

\begin{tabular}{|c|c|c|c|c|c|c|c|c|c|c|}
\hline & \multicolumn{4}{|c|}{ AD group $(n=26)$} & \multicolumn{4}{|c|}{ TD group $(n=26)$} & \multirow{2}{*}{$\begin{array}{c}\boldsymbol{t} \text {-test } \\
p\end{array}$} & \multirow{2}{*}{$\begin{array}{l}\text { Effect size } \\
\text { Cohen'sd }\end{array}$} \\
\hline & Min & Max & $M$ & $S D$ & Min & Max & $M$ & $S D$ & & \\
\hline Total rate of acts $\mathrm{p} / \mathrm{m}$ & 0.17 & 2.51 & 1.22 & 0.63 & 0.89 & 4.18 & 2.87 & 0.81 & $<.001^{*}$ & $2.32^{\mathrm{a}}$ \\
\hline \multicolumn{11}{|l|}{ Functions - rate $\mathrm{p} / \mathrm{m}$ : } \\
\hline Behavior Regulation (rate) & 0.17 & 1.66 & 0.74 & 0.36 & 0.37 & 1.78 & 1.02 & 0.38 & .009 & - \\
\hline Social Interaction (rate) & 0.00 & 0.33 & 0.06 & 0.09 & 0.05 & 0.50 & 0.24 & 0.14 & $<.001^{*}$ & $1.56^{\mathrm{a}}$ \\
\hline Joint Attention (rate) & 0.00 & 1.27 & 0.42 & 0.43 & 0.32 & 2.50 & 1.61 & 0.63 & $<.001^{*}$ & $2.25^{\mathrm{a}}$ \\
\hline Function Unclear (rate) ${ }^{\mathrm{b}}$ & 0.00 & 0.69 & 0.18 & 0.20 & 0.00 & 0.10 & 0.01 & 0.03 & $<.001^{*}$ & $1.21^{\mathrm{a}}$ \\
\hline \multicolumn{11}{|l|}{ Functions - proportion: } \\
\hline Behavior Regulation (\%) & 14 & 100 & 68.7 & 25.8 & 18 & 68 & 36.7 & 13.0 & $<.001^{*}$ & $1.47^{\mathrm{a}}$ \\
\hline Social Interaction (\%) & 0 & 27 & 4.7 & 6.9 & 2 & 16 & 8.6 & 4.6 & .021 & - \\
\hline Joint Attention (\%) & 0 & 78 & 26.6 & 23.2 & 26 & 73 & 54.7 & 12.8 & $<.001^{*}$ & $1.49^{a}$ \\
\hline
\end{tabular}

It is evident that children with $A D$ communicated less frequently than TD children, $t_{(50)}=-8.2, p<$ .001 , Cohen's $d=2.3$, large effect. The AD group communicated significantly less often for most of the communicative functions. However, acts with an unclear function occurred more frequently 
within the AD group. All subsequent comparisons between the groups were based on both rate and percentages of the total amount of communicative acts. In this way, communicative patterns could also be studied independent of the frequency of communicative acts.

When children in the AD group did communicate, it concerned acts to regulate the behavior of others most of the time, whereas communication for social purposes ( $\mathrm{SI}$ and JA) was less represented. The high standard deviations for all functions are remarkable. In the TD group, the proportion of communicative acts for joint attention was much higher than for behavior regulation. In both groups, acts for social interaction were less common. $T$-tests showed that in terms of percentages $A D$ children communicated significantly more often for behavior regulation than TD children $\left(t_{(50)}=5.2, p<.001\right.$, Cohen's $d=1.5$, large effect), and TD children communicated more often for joint attention than AD children ( $t_{(50)}=-5.3, p<.001$, Cohen's $d=1.5$, large effect) (see Table 3.3).

Profile analysis revealed a significant difference in profiles between the two groups, Greenhouse-Geisser adjusted $F_{(1.10,54.93)}=27.40, p<.001$. The profiles of the two groups are presented in Figure 3.1.

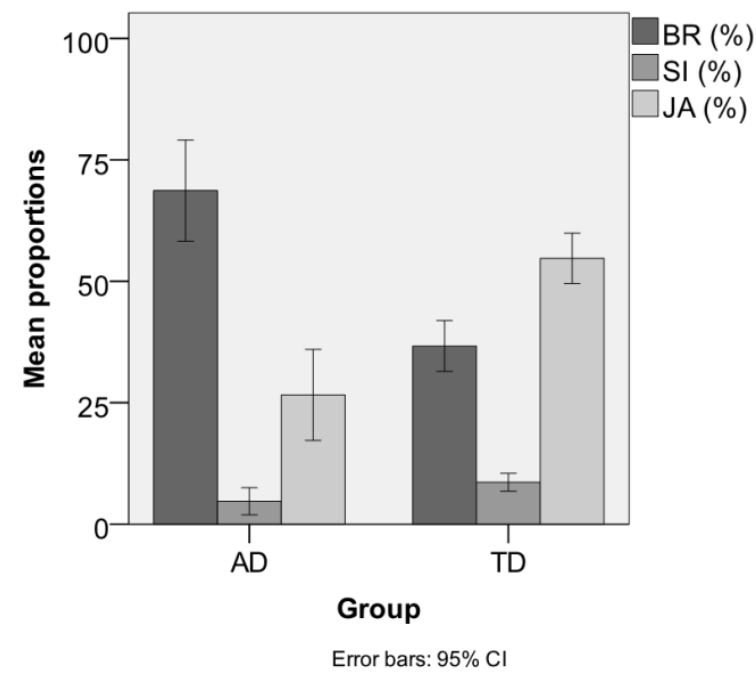

Note. $\mathrm{BR}=$ behavior regulation; $\mathrm{SI}=$ social interaction; $\mathrm{JA}=$ joint attention

Figure 3.1 Communication profiles for AD and TD group

Within the $A D$ group and the TD group, significant differences between the mean proportions of communicative functions were found (AD group: Greenhouse-Geisser adjusted $F_{(1.07,}$ ${ }_{26.80)}=35.12, p<.001 ;$ TD group: Greenhouse-Geisser adjusted $\left.F_{(1.17,29.26)}=71.06, p<.001\right)$. Pairwise comparisons revealed significant differences between the proportions of all three functions within the groups. In the AD group the mean proportion of social interaction was the lowest, behavior regulation was the highest, and joint attention was positioned in between, whereas in the TD group the results were the same for social interaction, but exactly the opposite for behavior regulation and joint attention (Bonferroni: $p s<.01$ ) (see Figure 3.1).

\section{Communicative functions in relation to verbal and nonverbal abilities}

Correlations between chronological age, nonverbal intelligence, expressive and receptive language development, and use of communicative functions were computed separately for both groups (see Table 3.4). 
Receptive and expressive language were highly correlated with each other in the AD group $\left(r_{(24)}=.96, p<.001\right)$, though the relation with nonverbal mental age was much weaker $\left(r_{(24)}=.60\right.$ and $r=.58$ respectively; $p s<.01)$. Strong significant negative correlations were found between both receptive and expressive language and the proportion of communicative acts for behavior regulation $\left(r_{(24)}=-.70\right.$ and $\left.r_{(24)}=-.69, p s<.001\right)$, and also strong significant positive correlations with acts for joint attention $\left(r_{(24)}=.70\right.$ and $\left.r_{(24)}=.71, p s<.001\right)$. The correlations between the functions and chronological age or nonverbal intelligence were weak or only modest in the AD group.

Table 3.4 Correlations between age, nonverbal intelligence, language abilities, and communicative functions for $A D$ and TD group

\begin{tabular}{lcccc}
\hline & Age & $\begin{array}{c}\text { Nonverbal } \\
\text { mental age }\end{array}$ & $\begin{array}{c}\text { Receptive } \\
\text { language }\end{array}$ & $\begin{array}{c}\text { Expressive } \\
\text { language }\end{array}$ \\
\hline AD group $(n=26)$ & & & & \\
$\quad$ Total rate of communicative acts & -.07 & .34 & $.60^{*}$ & .52 \\
Behavior Regulation (\%) & -.15 & -.34 & $-.70^{*}$ & $-.69^{*}$ \\
Social Interaction (\%) & .14 & -.11 & .04 & .04 \\
Joint Attention (\%) & .16 & .44 & $.70^{*}$ & $.71^{*}$ \\
TD group ( $n=26)$ & & & & .17 \\
Total rate of communicative acts & .24 & .11 &. .55 \\
Behavior Regulation (\%) & -.52 & -.50 & -.50 & -.52 \\
Social Interaction (\%) & .09 & .15 & .19 & .06 \\
Joint Attention (\%) & .52 & .47 & .46 & .52 \\
${ }^{*} p<.0015$ (adjusted significance level after Bonferroni correction) & &
\end{tabular}

Nonverbal mental age and both language comprehension and production were strongly related to each other and to chronological age in the TD group $\left(r_{(24)}=.72\right.$ and higher, $\left.p s<.001\right)$. The relationships between these three developmental aspects and the proportion of communicative acts for behavior regulation and joint attention were only moderate in the TD group $\left(r_{(24)}\right.$ ranges from () .46 to .52 , ps <.05), and no significant correlations with social interaction were found.

\section{Communicative functions in nonverbal versus verbal children with $A D$}

In Table 3.5 the results of the nonverbal and verbal AD group are presented separately and compared with each other and the TD group. The verbal AD group is positioned between the nonverbal $A D$ group and the TD group in total rate of communicative acts, with significant differences between the three groups, $F_{(2,49)}=44.7, p<.001, \eta^{2}=.14$, large effect (see Table 3.5). The same pattern is more or less visible for the mean rates for the three different functions, but differences are not significant for behavior regulation. The verbal AD group demonstrated the highest rate of unclear communicative acts. 
Table 3.5 Differences between nonverbal and verbal AD groups in use of communicative functions

\begin{tabular}{|c|c|c|c|c|c|c|c|c|c|c|}
\hline & \multicolumn{2}{|c|}{$\begin{array}{c}\text { AD1 } \\
\text { nonverbal } \\
(n=13)\end{array}$} & \multicolumn{2}{|c|}{$\begin{array}{c}\text { AD2 } \\
\text { verbal } \\
(n=13)\end{array}$} & \multicolumn{2}{|c|}{$\begin{array}{c}\text { TD } \\
(n=26)\end{array}$} & \multicolumn{2}{|c|}{ ANOVA } & \multirow{2}{*}{$\begin{array}{c}\text { Effect } \\
\text { size } \\
\eta^{2} \\
\end{array}$} & \multirow{2}{*}{$\begin{array}{l}\text { Post-hoc tests } \\
\text { Games-Howell }\end{array}$} \\
\hline & $M$ & $S D$ & $M$ & $S D$ & $M$ & $S D$ & $F$ & $p$ & & \\
\hline Total rate of acts $\mathrm{p} / \mathrm{m}$ & 0.81 & 0.42 & 1.64 & 0.52 & 2.87 & 0.81 & 44.7 & $<.001^{*}$ & $.14^{\mathrm{a}}$ & $\mathrm{AD} 1<\mathrm{AD} 2<\mathrm{TD}$ \\
\hline \multicolumn{11}{|l|}{ Functions - rate $\mathrm{p} / \mathrm{m}$ : } \\
\hline Behavior Regulation & 0.65 & 0.37 & 0.83 & 0.35 & 1.01 & 0.38 & 4.5 & .016 & - & - \\
\hline Social Interaction & 0.05 & 0.09 & 0.08 & 0.09 & 0.24 & 0.14 & 14.3 & $<.001^{*}$ & $.18^{\mathrm{a}}$ & $\mathrm{AD} 1 \& \mathrm{AD} 2<\mathrm{TD}$ \\
\hline Joint Attention & 0.11 & 0.17 & 0.73 & 0.40 & 1.61 & 0.63 & 42.5 & $<.001^{*}$ & $.24^{\mathrm{a}}$ & $\mathrm{AD} 1<\mathrm{AD} 2<\mathrm{TD}$ \\
\hline Function Unclear & 0.10 & 0.16 & 0.25 & 0.21 & 0.01 & 0.03 & 14.0 & $<.001^{*}$ & $.27^{\mathrm{a}}$ & $\mathrm{AD} 1 \& \mathrm{TD}<\mathrm{AD} 2$ \\
\hline \multicolumn{11}{|l|}{ Functions - proportion: } \\
\hline Behavior Regulation (\%) & 83.9 & 19.9 & 53.4 & 22.0 & 36.7 & 13.0 & 33.7 & $<.001^{*}$ & $.18^{a}$ & $\mathrm{TD} \& \mathrm{AD} 2<\mathrm{AD} 1$ \\
\hline Social Interaction (\%) & 4.9 & 8.6 & 4.5 & 5.0 & 8.6 & 4.6 & 2.8 & .069 & - & - \\
\hline Joint Attention (\%) & 11.1 & 13.9 & 42.1 & 20.3 & 54.7 & 12.8 & 32.6 & $<.001^{*}$ & $.15^{\mathrm{a}}$ & $\mathrm{AD} 1<\mathrm{AD} 2 \& \mathrm{TD}$ \\
\hline
\end{tabular}

The proportion of behavior regulation was much higher in the nonverbal $A D$ group than in the two other groups, $F_{(2,49)}=33.7, p<.001, \eta^{2}=.18$, large effect (see also Figure 3.2). Nearly half of the nonverbal group $(n=6)$ did not show any acts for social interaction or joint attention at all, whereas in the verbal AD group and the TD group, all children communicated for all three functions. Therefore, the proportion of joint attention in the nonverbal $A D$ group was significantly lower than in the verbal $A D$ and TD groups, $F_{(2,49)}=32.6, p<.001, \eta^{2}=.15$, large effect. Post-hoc tests showed no difference between the verbal $A D$ group and the TD group in the proportion of both behavior regulation and joint attention $(p>.05$ ) (Table 3.5). Though the profiles of the verbal AD group and the TD group were not significantly different, the verbal AD group showed a relatively higher mean score for behavior regulation compared to joint attention. Since the nonverbal AD group differed from the verbal $A D$ group and the TD group on nonverbal mental age, the analyses were rerun using nonverbal mental age as covariate. These results indicate that the covariate did not influence the results of the analyses of variance.

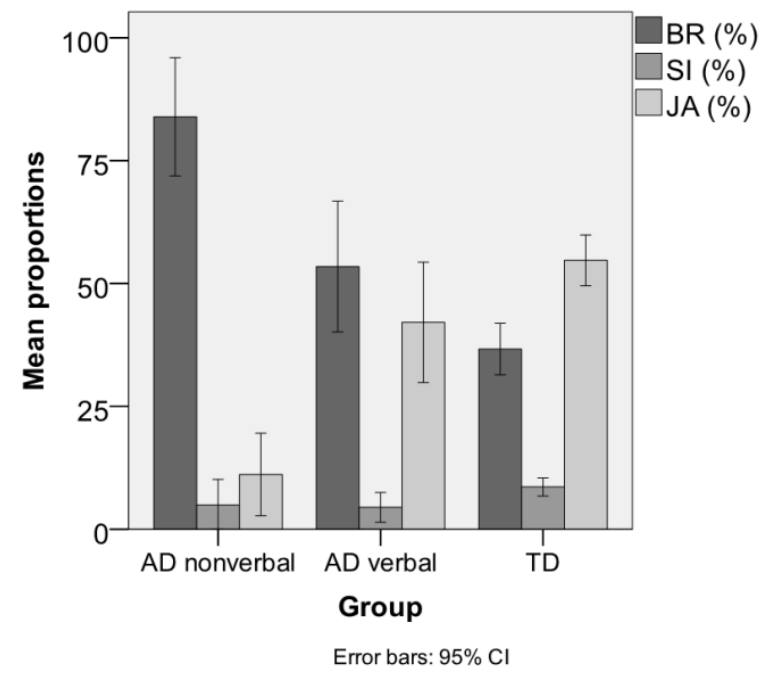

Note. $\mathrm{BR}=$ behavior regulation; $\mathrm{SI}=$ social interaction; $\mathrm{JA}=$ joint attention

Figure 3.2 Communication profiles for AD groups and TD group 


\section{Differences in complexity of communicative forms}

In order to examine the complexity of communicative forms used for the different communicative functions, proportions were calculated for three different levels of complexity from the total acts per function. Table 3.6 shows the proportion of complexity levels used for the functions behavior regulation and joint attention. Social interaction was excluded because of the low rates of communicative acts for this function in all three groups.

Analyses of the acts for behavior regulation revealed that children in the nonverbal $A D$ group used the least complex form significantly more often than the TD group and the verbal AD group. However, the combination of communicative forms used by verbal children with AD was only significantly distinct from the TD group at the most complex level, that is the combination of a gesture, verbalization, and eye gaze $(p=.009)$. For behavior regulation, the verbal AD group showed a significant higher complexity of communicative forms than the nonverbal AD group. In comparison to the TD group, significant differences only were found at the highest level of complexity. Post hoc analyses on the joint attention data indicated that both AD groups used forms with an intermediate level of complexity more often than the TD group and combined three different communicative forms significantly less in comparison with the TD group. In other words, the level of complexity is significantly lower in both the nonverbal and the verbal AD groups than in the TD group.

Table 3.6 Differences between AD and TD groups in levels of complexity of communicative forms

\begin{tabular}{|c|c|c|c|c|c|c|c|c|c|c|}
\hline & \multicolumn{2}{|c|}{$\begin{array}{c}\text { AD1 } \\
\text { nonverbal } \\
(n=13)\end{array}$} & \multicolumn{2}{|c|}{$\begin{array}{c}\text { AD2 } \\
\text { verbal } \\
(n=13)\end{array}$} & \multicolumn{2}{|c|}{$\begin{array}{c}\text { TD } \\
(n=26)\end{array}$} & \multicolumn{2}{|c|}{ ANOVA } & \multirow{2}{*}{$\begin{array}{c}\text { Effect } \\
\text { size } \\
\eta^{2} \\
\end{array}$} & \multirow{2}{*}{$\begin{array}{c}\text { Post-hoc tests } \\
\text { Bonferroni }\end{array}$} \\
\hline & $M$ & $S D$ & $M$ & $S D$ & $M$ & $S D$ & $F$ & $p$ & & \\
\hline \multicolumn{11}{|l|}{ Behavior Regulation } \\
\hline Complexity 1 (\%) & 49.9 & 20.9 & 14.0 & 12.4 & 10.0 & 9.9 & 37.6 & $<.001^{*}$ & $.32^{\mathrm{a}}$ & $A D 2 \& T D<A D 1$ \\
\hline Complexity 2 (\%) & 41.1 & 18.2 & 68.1 & 11.5 & 58.6 & 15.0 & 10.9 & $<.001^{*}$ & $.03^{c}$ & $A D 1<A D 2 \& T D$ \\
\hline Complexity 3 (\%) & 9.1 & 12.1 & 17.9 & 11.9 & 31.4 & 13.5 & 14.4 & $<.001^{*}$ & $.12^{\mathrm{b}}$ & $A D 1 \& A D 2<T D$ \\
\hline Joint Attention & \multicolumn{2}{|c|}{$(n=7)^{d}$} & \multicolumn{2}{|c|}{$(n=13)$} & \multicolumn{2}{|c|}{$(n=26)$} & & & & \\
\hline Complexity $1(\%)^{\mathrm{e}}$ & - & - & - & - & - & - & - & - & - & - \\
\hline Complexity 2 (\%) & 93.5 & 17.2 & 88.4 & 10.8 & 77.2 & 12.0 & 11.2 & $<.001^{*}$ & $.03^{c}$ & $\mathrm{TD}<\mathrm{AD} 1 \& \mathrm{AD} 2$ \\
\hline Complexity $3(\%)$ & 6.5 & 17.2 & 11.2 & 10.4 & 22.4 & 11.7 & 6.3 & $.004^{*}$ & $.09^{b}$ & $\mathrm{AD} 1 \& \mathrm{AD} 2<\mathrm{TD}$ \\
\hline
\end{tabular}

${ }^{*} p<.01$ (adjusted significance level after Bonferroni correction)

a large effect size; ${ }^{\mathrm{b}}$ medium effect size; ${ }^{\mathrm{c}}$ small effect size; ${ }^{\mathrm{d}} 6$ children did not show any communicative acts for joint attention; ${ }^{e}$ percentages were too small to analyze

\section{Discussion}

Communication problems in individuals with ASD and associated ID are often very severe and heterogeneous (Boucher et al., 2007). The goal of our study was to describe the communication abilities of low-functioning children with autism (AD) in a comprehensive way by examining both communicative functions and complexity of communicative forms. Communication profiles of lowfunctioning verbal and nonverbal children with $A D$ were compared with those in a control group consisting of typically developing children. The children were individually matched on nonverbal developmental level. 


\section{Rate and functions of communication in low-functioning children with autism}

The results of this study indicated that the amount of intentional communication is significantly lower in children with co-occurring $A D$ and $I D$ than in typically developing children with a comparable developmental level. Reduced frequency of communication is one of the core deficits of ASD, appearing already at a very young age, as demonstrated in several studies on toddlers (Landa et al., 2007). Our study focused on older children with $A D$ and a co-occurring ID, thus the results indicate that the amount of intentional communication remains reduced while growing up. The lower frequency of communication can reflect a lower intrinsic motivation to communicate and interact with others, or it can be due to a reduced ability to initiate social bids and respond to the social environment, resulting in fewer opportunities to influence the social environment (Shumway \& Wetherby, 2009).

With regard to the functions of communication, the results of our study indicated that lowfunctioning children with $A D$ show a specific communication profile as compared to typically developing children. Children with $A D$ and ID prefer to communicate for the purpose of behavior regulation rather than social interaction and joint attention, while in TD children the opposite profile is present. A previous study found the same profile in very young children with ASD (Shumway \& Wetherby, 2009). Communication for behavior regulation, such as requesting or protesting, can be characterized as less complex and less social than communication for joint attention purposes (Landa, 2007; Wetherby et al., 1997). To learn to interact with others, children need to pay attention to socially relevant stimuli, such as faces and voices, in their environment. Several studies have shown that from early on children with ASD are less focused on such stimuli (Dawson et al., 1998; Klin et al., 2003). As a consequence, children with ASD participate less frequently in social interactions, which impedes the development of social cognitive abilities, such as joint attention (Dawson et al., 2004; Klin et al., 2002).

\section{Communication profiles of nonverbal and verbal children with autism}

A considerable amount of heterogeneity in communication was observed within the AD group. For example, some children with AD communicated only a few times during the whole assessment, and all communicative acts served the purpose of behavior regulation, while other children with $A D$ communicated as often as TD children, even for joint attention purposes. Language development (both expressive and receptive) showed the strongest relation with the proportional use of communication for behavior regulation and joint attention compared to other characteristics, such as chronological age and nonverbal mental age. The development of joint attention is usually intertwined with that of language acquisition: joint attention is essential to create shared situations, in which children can learn from the language of others, but the acquisition of language also increases the possibilities for joint attention, because the scope of situations extends from present objects and activities to objects out of sight, future and past events, and internal states (Adamson et al., 2009; Carpenter \& Tomasello, 2000).

In order to further explore the role of language, communication profiles were examined in both a verbal and a nonverbal subgroup of children with AD. In our study, low-functioning nonverbal children with $A D$ showed the most atypical and limited communication profile compared to verbal children with $A D$ and typically developing children. These findings are in line with the results of the study by Stone and Caro-Martinez (1990) in which verbal and nonverbal children with AD (including children with and without ID) were compared in a naturalistic setting. Communicative acts for social 
purposes seemed to be strongly related to language abilities in low-functioning children with AD. Nearly half of the nonverbal group in our study did not show any communication aimed at social interaction or joint attention, and the other half only for a very small part. In contrast, typically developing children are able already before language development to communicate extensively for social interaction and joint attention (Coupe O'Kane \& Goldbart, 1998; Wetherby et al., 1997). On the basis of the results of this study, communication on the part of low-functioning nonverbal children with $A D$ can mainly be characterized as communication intended to regulate somebody else's behavior, to obtain or protest against certain objects or activities. Furthermore, these children communicate by means of very primitive forms of the least complex level, such as manipulations of persons or objects and movements of objects or simple gestures. Nonverbal children with AD have very restricted communicative abilities to express their needs and desires to others, and consequently are less able to influence their social environment. It is harder to understand nonverbal children with $A D$, especially for unfamiliar individuals, since these children use very unconventional and sometimes very subtle ways to communicate (Wetherby et al., 1997). Particularly in the nonverbal group, challenging behavior is often seen and this may be used for communicative ends (Schuler et al., 1997).

In our study, significant differences in frequency of communicative acts were found between verbal children with $A D$ and TD children, but there were no differences in the proportional use of the communicative functions between these two groups. This suggests that in the verbal group with $A D$ differences in the use of communicative functions as compared to TD children are quantitative rather than qualitative in nature. However, only basic communicative functions were included in this study. The higher rate of communication for unclear functions in the verbal group as compared to both other groups may be explained by the amount of echolalia or other aberrant language features observed in this group. The verbal AD group made more efforts to communicate, as the rate of communication was significantly higher than in the nonverbal AD group, but these children were not always successful in communicating their intentions in an effective way. Low-functioning verbal children with $A D$ also differ significantly from nonverbal children with $A D$ in the proportion of communicative acts for the purpose of joint attention. In a previous study by Stone and CaroMartinez (1990) the same differences between verbal and nonverbal children with AD were found during observations in a naturalistic setting. With respect to forms, verbal children with AD were more likely to use a combination of two communicative forms instead of three than TD children for both behavior regulation and joint attention.

\section{Limitations and recommendations for future research}

Using observational methods permits an examination of communication patterns in low-functioning individuals with $A D$ in great detail. As such, this is a valuable technique in research into ID, since no standardized tests for communication are available which provide norms for this low-functioning population. However, there are some methodological issues that limit the strengths of the present findings. The first limitation concerns the small sample size, in particular when specific subsamples were examined. Nevertheless, the number of participants compares well with other studies on communication profiles. Second, the situations of the CSBS-DP are specifically developed to elicit communicative behavior and are not completely comparable to communication in daily life. However, a standardized observational measurement procedure, such as the CSBS-DP provides a more stable estimate of a child's true performance, because error introduced through uncontrolled 
factors is minimized (Yoder \& Symons, 2010). The CSBS situations mainly focused on behavior regulation and joint attention, because most items are designed for triadic interaction, i.e., personobject-person or object-person-object interaction, resulting in a possible underestimation of the level of social interaction and overestimation of the proportions for the other two functions. Therefore, future studies should examine communication during more varied activities, including social activities without play materials. Another weakness of this study concerns the sex difference between the AD and TD groups. A comparison group matched on sex is recommended for future research. In addition, it would be useful to have a control group of verbal and nonverbal children with an ID without ASD and a comparison group consisting of children with AD without ID. In this way it is possible to control for the effect of experience and to analyze which characteristics may be due to the AD diagnosis and which to the ID diagnosis. In this study the TD control group was matched on nonverbal mental age, not on chronological age, in order to create groups of comparable levels of functioning.

\section{Implications for clinical practice}

More insight into communication strengths and difficulties in low-functioning children with $A D$ is valuable for both assessment and treatment goals. Knowledge of the child's actual communication level regarding functions and forms can change the caregivers' expectations and subsequently their communication strategies (Yoder \& Warren, 2001). Because of the heterogeneity in the lowfunctioning $A D$ group, an individual approach regarding assessment and intervention is necessary. $A$ comprehensive evaluation of communication, with respect to both functions and forms, is recommended to choose the intervention best suited for improving communication abilities.

The use of basic communicative functions is impaired mainly in low-functioning nonverbal children with AD. Several treatment strategies have been developed to stimulate the communication abilities of children with ASD. In most cases the focus of these interventions is on improvement in the use of communicative forms, especially language, or the development of one specific function, namely joint attention. In line with the results of this study, improvement of communicative intentionality seems to be equally or even more important than an emphasis on communicative forms. After all, the ability to use (conventional) communicative forms is useless when children do not know how and when to communicate their needs and desires (Schuler et al., 1997; Wetherby et al., 1997). Purposefully communicative behavior enables a child to influence the environment and has a positive influence on other developmental aspects (Coupe O'Kane \& Goldbart, 1998). Therefore, establishment of intentionality and expansion of the range of communicative functions are important goals for interventions in low-functioning nonverbal children with $A D$. To accomplish these aims individual strengths, motivations, and preferred activities are useful starting points (Schuler et al., 1997). It is possible to stimulate intentionality, for example by interrupting well-known routines, placing a favorite play object out of reach, or encouraging the child to choose between favorite snacks or activities. Other developmental aspects, such as the presence or absence of object permanence, are important to determine how and in which situations communication may be encouraged.

Regarding low-functioning verbal children with $A D$ the focus of communication intervention shifts to the effective use of conventional communication forms and skills in more complex situations. Since verbal children with $A D$ try to initiate communication much more often than 
nonverbal children with $A D$, but also commit more communicative acts with an unclear function, the results suggest that some of these children are making an effort to communicate, but do not always succeed in communicating their intention in an effective way. This group may be particularly ripe for interventions focusing on the improvement of the quality and diversity of communicative functions and the use of more conventional ways to communicate. Intervention goals need to be based on individual needs and may also lie beyond the scope of this study, such as vocabulary expansion, supporting specific pragmatic skills, and stimulating communication about decontextualized topics (Tager-Flusberg et al., 2005).

The generic goals for interventions described above, all concentrated on expressive communication, since our study focused on initiation of intentional communication. Especially in the case of children with $A D$ and ID, problems in receptive communication are usually even more severe than problems in expressive communication. Therefore, stimulation of communicative competence should be focused on the support of receptive communication as well (Noens \& Van BerckelaerOnnes, 2004).

\section{Conclusions}

Since our study focused on a particular subgroup - children with co-occurring AD and ID - which is often neglected in research, it constitutes an important contribution to the current knowledge on communication in ASD. Characteristics of children with co-occurring AD and ID are not comparable to characteristics of other subgroups of children with ASD right away and need to be studied separately. The results of this study suggest that communication profiles in low-functioning children with $A D$ are extremely variable. A striking difference between the profiles of verbal and nonverbal children with $A D$ and ID was found. Communication in nonverbal children with $A D$ was very limited and mainly served imperative purposes to regulate behaviors of others. Verbal children with $A D$ communicated more often for declarative purposes, such as joint attention, than the nonverbal subgroup. The nonverbal AD group used less complex forms of communication in comparison to the verbal $A D$ group and typically developing children with a comparable developmental level. The verbal $A D$ group differed from typically developing children only in rate of communication, not in proportion of communication for specific functions. Only at the most complex level of communicative forms (a combination of three different forms) a significant difference in complexity was found between the verbal AD group and the TD group. The results of this study indicate the presence of severe communication impairments in low-functioning children with ASD, especially in nonverbal children, and emphasize the importance of suitable communication interventions for this vulnerable group.

\section{References}

Adamson, L. B., Bakeman, R., Deckner, D. F., \& Romski, M. A. (2009). Joint engagement and the emergence of language in children with autism and Down syndrome. Journal of Autism and Developmental Disorders, 39, 84-96.

Adrien, J. L., Rossignol-Deletang, N., Martineau, J., Couturier, G., \& Barthelemy, C. (2001). Regulation of cognitive activity and early communication development in young autistic, mentally retarded and young normal children. Developmental Psychobiology, 39, 124-136.

American Psychiatric Association [APA] (2000). Diagnostic and Statistical Manual of Mental Disorders (4th ed., text revision). Washington, DC: APA. 
Bates, E. (1979). Intentions, conventions, and symbols. In E. Bates, L. Benigni, I. Bretherton, L. Camaioni, \& V. Volterra (Eds.), The emergence of symbols: Cognition and communication in infancy (pp. 33-68). New York, NY: Academic.

Bebko, J. M., Konstantareas, M. M., \& Springer, J. (1987). Parent and professional evaluations of family stress associated with characteristics of autism. Journal of Autism and Developmental Disorders, 1, 565-576.

Bloom, L., \& Tinker, E. (2001). The intentionality model and language acquisition: Engagement, effort, and the essential tension in development. Monographs of the Society for Research in Child Development, 66, 1-89.

Boucher, J., Mayes, A., \& Bigham, S. (2007). Memory, language and intellectual ability in low-functioning autism. In: J. Boucher \& D. Bowler (Eds.), Memory in autism: Theory and evidence (pp. 268-290). Cambridge, UK: Cambridge University Press.

Bruinsma, Y., Koegel, R. L., \& Koegel, L. K. (2004). Joint attention and children with autism: A review of the literature. Mental Retardation and Developmental Disabilities Research Reviews, 10, 169-174.

Buckley, B. (2003). Children's communicative skills. From birth to five years. London, UK: Routledge.

Calloway, C. J., Myles, B. S., \& Earles, T. L. (1999). The development of communicative functions and means in students with autism. Focus on Autism and Other Developmental Disabilities, 14, 140-149.

Camaioni, L., Perucchini, P., Muratori, F., Parrini, B., \& Cesari, A. (2003). The communicative use of pointing in autism: Developmental profile and factors related to change. European Psychiatry, 18, 6-12.

Carpenter, M., Nagell, K., Tomasello, M., Butterworth, G., \& Moore, C. (1998). Social cognition, joint attention, and communicative competence from 9 to 15 . Monographs of the Society for Research in Child Development, 63, 1-174.

Carpenter, M., \& Tomasello, M. (2000). Joint attention, cultural learning, and language acquisition: Implications for children with autism. In A. M. Wetherby, \& B. M. Prizant (Eds.), Autism spectrum disorders: A transactional developmental perspective (pp. 31-54). Baltimore, MD: Brookes.

Charman, T., Baron-Cohen, S., Swettenham, J., Baird, G., Drew, A., \& Cox, A. (2003). Predicting language outcome in infants with autism and pervasive developmental disorder. International Journal of Language and Communication Disorders, 38, 265-285.

Chiang, C.-H., Song, W.-T., Lin, T.-L., \& Rogers, S. J. (2008). Nonverbal communication skills in young children with autism. Journal of Autism and Developmental Disorders, 38, 1898-1906.

Chiang, H.-M. (2008). Expressive communication of children with autism: The use of challenging behavior. Journal of Intellectual Disability Research, 52, 966-972.

Cohen, J., Cohen, P., West, S. G., \& Aiken, L. S. (2003). Applied multiple regression/correlation analysis for the behavioral sciences. Mahwah, NJ: Lawrence Erlbaum.

Colgan, S. E., Lanter, E., McComish, C., Watson, L. R., Crais, E. R., \& Baranek, G. T. (2006). Analysis of social interaction gestures in infants with autism. Child Neuropsychology, 12, 307-319.

Coupe O'Kane, J., \& Goldbart, J. (1998). Communication before speech: Development and assessment. London, UK: David Fulton Publishers.

Crais, E., Douglas, D. D., \& Campbell, C. C. (2004). The intersection of the development of gestures and intentionality. Journal of Speech, Language, and Hearing Research, 47, 678-694.

Dawson, G., Meltzoff, A. N., Osterling, J., Rinaldi, J., \& Brown, E. (1998). Children with autism fail to orient to naturally occurring social stimuli. Journal of Autism and Developmental Disorders, 28, 479-485.

Dawson, G., Toth, K., Abbott, R., Osterling, J., Munson, J., Estes, A., \& Liaw, J. (2004). Early social attention impairments in autism: Social orienting, joint attention, and attention to distress. Developmental Psychology, 40, 271-283.

Delinicolas, E. K., \& Young, R. L. (2007). Joint attention, language, social relating, and stereotypical behaviors in children with autistic disorder. Autism, 11, 425-436.

Drew, A., Baird, G., Taylor, E., Milne, E., \& Charman, T. (2007). The Social Communication Assessment for Toddlers with Autism (SCATA): An instrument to measure the frequency, form and function of communication in toddlers with autism spectrum disorder. Journal of Autism and Developmental Disorders, 37, 648-666.

Eagle, R. S. (2002). Accessing and assessing intelligence in individuals with lower functioning autism. Journal of Developmental Disabilities, 9, 45-53.

Evers, A., Braak, M. S. L., Frima, R. M., \& Van Vliet-Mulder, J. C. (2009). Commissie Testaangelegenheden Nederland Documentatie [Committee for Psychometric Evaluation of Psychological Tests of the Dutch Institute of Psychologists - Documentation]. Amsterdam, NL: Boom Test Uitgevers.

Freeman, N. L., Perry, A., \& Bebko, J. M. (2002). Behavior is communication: Nonverbal communicative behavior in students with autism and instructors' responsivity. Journal on Developmental Disabilities, 9, 145-155.

Goldstein, H. (2002). Communication intervention for children with autism: A review of treatment efficacy. Journal of Autism and Developmental Disorders, 32, 373-396.

Goodhart, F., \& Baron-Cohen, S. (1993). How many ways can the point be made? Evidence from children with and without autism. First Language, 13, 225-233.

Gotham, K., Risi, S., Pickles, A., \& Lord, C. (2007). The Autism Diagnostic Observation Schedule: Revised algorithms for improved diagnostic validity. Journal of Autism and Developmental Disabilities, 37, 613-627.

lacono, T., Carter, M., \& Hook, J. (1998). Identification of intentional communication in students with severe and multiple disabilities. Augmentative and Alternative Communication, 14, 102-114.

Klin, A., Jones, W., Schultz, R., \& Volkmar, F. (2003). The enactive mind, or from actions to cognition: Lessons from autism. Philosophical Transactions of the Royal Society of London, 358, 345-360. 
Klin, A., Jones, W., Schultz, R., Volkmar, F., \& Cohen, D. (2002). Visual fixation patterns during viewing of naturalistic social situations as predictors of social competence in individuals with autism. Archives of General Psychiatry, 59, 809816.

Konstantareas, M. M., \& Homatidis, S. (1989). Assessing child symptom severity and stress in parents of autistic children. Journal of Child Psychology and Psychiatry, 30, 459-470.

Landa, R. (2007). Early communication development and intervention for children with autism. Mental Retardation and Developmental Disabilities Research Reviews, 13, 16-25.

Landa, R. J., Holman, K. C., \& Garrett-Mayer, E. (2007). Social and communication development in toddlers with early and later diagnosis of autism spectrum disorders. Archives of General Psychiatry, 64, 853-864.

Lecavalier, L., Leone, S., \& Wiltz, J. (2006). The impact of behavior problems on caregiver stress in young people with autism spectrum disorders. Journal of Intellectual Disability Research, 50, 172-183.

Lord, C., Risi, S., \& Pickles, A. (2004). Trajectory of language development in autistic spectrum disorders. In M. L. Rice \& S. F. Warren (Eds.), Developmental language disorders: From phenotypes to etiologies (pp. 7-29). Mahwah, NJ: Lawrence Erlbaum Associates.

Mawhood, L., Howlin, P., \& Rutter, M. (2000). Autism and developmental receptive language disorder: A comparative follow-up in early adult life. I: Cognitive and language outcomes. Journal of Child Psychology and Psychiatry, 41, 547-559.

McClintock, K., Hall, S., \& Oliver, C. (2003). Risk markers associated with challenging behaviors in people with intellectual disabilities: A meta-analytic study. Journal of Intellectual Disability Research, 47, 405-416.

McDuffie, A., Yoder, P., \& Stone, W. (2005). Prelinguistic predictors of vocabulary in young children with autism spectrum disorders. Journal of Speech, Language and Hearing Research, 48, 1080-1097.

Mundy, P., \& Gomes, A. (1998). Individual differences in joint attention skill development in the second year. Infant Behavior and Development, 21, 469-482.

Mundy, P., Kasari, C., Sigman, M., \& Ruskin, E. (1995). Nonverbal communication and early language acquisition in children with Down syndrome and in normally developing children. Journal of Speech and Hearing Research, 38, 157167.

Mundy, P., Sigman, M., \& Kasari, C. (1990). A longitudinal study of joint attention and language development in autistic children. Journal of Autism and Developmental Disorders, 20, 115-128.

Noens, I., \& Van Berckelaer-Onnes, I. A. (2004). Making sense in a fragmentary world: Communication in people with autism and learning disability. Autism, 8, 197-218.

Noens, I., \& Van Berckelaer-Onnes, I. A. (2005). Captured by details: Sense-making, language and communication in autism. Journal of Communication Disorders, 38, 123-141.

Reynell, J. K. (1985). Reynell Developmental Language Scales. Windsor, UK: NFER-Nelson.

Schlichting, J. E. P. T., Van Eldik, M. C. M., Spelberg, H. C., Van der Meulen, S., \& Van der Meulen, B. F. (1995). Schlichting Test voor Taalproductie. [Schlichting Test for Language production]. Nijmegen, NL: Berkhout.

Schuler, A. L., Prizant, B. M., \& Wetherby, A. M. (1997). Enhancing language and communication development: Prelinguistic approaches. In D.J. Cohen \& F.R. Volkmar (Eds.), Handbook of autism and pervasive developmental disorders (2nd ed., pp. 513-538). New York, NY: John Wiley \& Sons.

Shumway, S., \& Wetherby, A. M. (2009). Communicative acts of children with autism spectrum disorders in the second year of life. Journal of Speech, Language, and Hearing Research, 52, 1139-1156.

Sigafoos, J. (2000). Communication development and aberrant behavior in children with developmental disabilities. Education and Training in Mental Retardation and Developmental Disabilities, 35, 168-176.

Stone, W. L., \& Caro-Martinez, L. M. (1990). Naturalistic observations of spontaneous communication in autistic children. Journal of Autism and Developmental Disorders, 20, 437-453.

Stone, W. L., Ousley, O. Y., Yoder, P. J., Hogan, K. L., \& Hepburn, S. L. (1997). Nonverbal communication in two- and three-year-old children with autism. Journal of Autism and Developmental Disorders, 27, 677-696.

Tager-Flusberg, H., Paul, R., \& Lord, C. (2005). Language and communication in autism. In F. R. Volkmar, R. Paul, A. Klin, \& D. Cohen (Eds.), Handbook of autism and pervasive developmental disorders. Volume I: Diagnosis, development, neurobiology, and behavior (3rd ed.) (pp. 335-364). Hoboken, NJ: Wiley.

Tellegen, P. J., Winkel, M., Wijnberg-Williams, B. J., \& Laros, J. A. (1998). Snijders-Oomen Niet-verbale intelligentietest, $S O N-R 2^{1 / 2-7}$ : handleiding en verantwoording. [Snijders-Oomen Non-verbal intelligence test, SON-R 21/2-7: Manual]. Lisse, NL: Swets \& Zeitlinger.

Travis, L. L., \& Sigman, M. (2001). Communicative intentions and symbols in autism: Examining a case of altered development. In J. A. Burack, T. Charman, N. Yirmiya \& P. R. Zelazo (Eds.), The development of autism. Perspectives from theory and research (pp. 279-308). Mahwah, NJ: Erlbaum.

Van Berckelaer-Onnes, I. A., Van Loon, J., \& Peelen, A. (2002). Challenging behaviour: A challenge to change. Autism, 8 , 123-124.

Van Eldik, M. C. M., Schlichting, J. E. P. T., Spelberg, H. C., Van der Meulen, S., \& Van der Meulen, B. F. (1995) Reynell Test voor Taalbegrip [Reynell Test for Language comprehension]. Nijmegen, NL: Berkhout.

Viellard, M., Da Fonseca, D., De Martino, S., Girardot, A. M., Bastard-Rosset, D., Duverger, H., ... \& Poinso, F. (2007). Autisme et retard mental: étude de la communication sociale précoce. Archives de Pédiatrie, 14, 234-238. 
Watt, N., Wetherby, A., \& Shumway, S. (2006). Prelinguistic predictors of language outcome at 3 years of age. Journal of Speech, Language, and Hearing Research, 49, 1224-1237.

Wetherby, A. (1986). Ontogeny of communicative functions in autism. Journal of Autism and Developmental Disorders, 16, 295-316.

Wetherby, A., \& Prizant, B. (1993). Communication and Symbolic Behavior Scales - Normed edition. Baltimore, MD: Paul H. Brookes.

Wetherby, A., \& Prizant, B. (2002). Communication and Symbolic Behavior Scales: Developmental Profile - First normed edition. Baltimore, MD: Paul H. Brookes.

Wetherby, A. M., Prizant, B. M., \& Schuler, A. L. (2000). Understanding the nature of communication and language impairments. In S. F. Warren, M. E. Frey (Series Eds.), A. M. Wetherby, \& B. M. Prizant (Vol. Eds.), Communication and language intervention series: Volume 9. Autism spectrum disorders: A transactional perspective (pp. 109-141). Baltimore, MD: Paul H. Brookes.

Wetherby, A., Schuler, A., \& Prizant, B. (1997). Enhancing language and communication development: Theoretical foundations. In D.J. Cohen \& F.R. Volkmar (Eds.), Handbook of autism and pervasive developmental disorders (2nd ed., pp. 513-538). New York, NY: John Wiley \& Sons.

Wetherby, A., Watt, N., Morgan, L., \& Shumway, S. (2007). Social communication profiles of children with autism spectrum disorders late in the second year of life. Journal of Autism and Developmental Disorders, 37, 960-975.

Wing, L. (2006). Diagnostic Interview for Social and Communication Disorders (11th ed.). Bromley, UK: Centre for Social and Communication Disorders.

Yoder, P., \& Symons, F. (2010). Observational measurement of behavior. New York, NY: Springer Publishing.

Yoder, P. J., \& Warren, S. F. (2001). Intentional communication elicits language-facilitating maternal responses in dyads with children who have developmental disabilities. American Journal on Mental Retardation, 106, 327-335. 